\title{
Early-Life Adversity Interacts with FKBP5 Genotypes: Altered Working Memory and Cardiac Stress Reactivity in the Oklahoma Family Health Patterns Project
}

\author{
William R Lovallo*,1,2, Mary-Anne Enoch ${ }^{3}$, Ashley Acheson, ${ }^{4,5}$, Andrew J Cohoon', Kristen H Sorocco ${ }^{1,6}$, \\ Colin A Hodgkinson ${ }^{3}$, Andrea S Vincent ${ }^{7}$ and David Goldman ${ }^{3}$ \\ 'VA Medical Center, Oklahoma City, OK, USA; '2Department of Psychiatry and Behavioral Sciences, University of Oklahoma Health Sciences Center, \\ Oklahoma City, OK, USA; ${ }^{3}$ Laboratory of Neurogenetics, NIH, NIAAA, Bethesda, MD, USA; ${ }^{4}$ Department of Psychiatry, University of Texas Health \\ Sciences Center at San Antonio, San Antonio, TX, USA; ${ }^{5}$ Research Imaging Institute, UTHSCSA, San Antonio, TX, USA; ${ }^{6}$ Donald W. Reynolds \\ Department of Geriatric Medicine, University of Oklahoma Health Sciences Center, Oklahoma City, OK, USA; ${ }^{7}$ Cognitive Science Research Center, \\ University of Oklahoma, Norman, OK, USA
}

\begin{abstract}
Exposure to stress during critical periods of development can have adverse effects on adult health behaviors, and genetic vulnerabilities may enhance these stress effects. We carried out an exploratory examination of psychological, physiological, and behavioral characteristics of 252 healthy young adults for the impact of early-life adversity (ELA) in relation to the G-to-A single nucleotide polymorphism (SNP), rs9296 I58, of the FKBP5 gene. FKBP5 is a molecular cochaperone that contributes to the functional status of the glucocorticoid receptor (GR) and to the quality of corticosteroid signaling. FKBP5 expression is upregulated by cortisol exposure during stressful episodes, with greater upregulation seen in A-allele carriers. As such, FKBP5 expression and GR function may be environmentally sensitive in A-allele carriers and therefore suitable for the study of gene-by-environment $(\mathrm{G} \times \mathrm{E})$ interactions. Compared with FKBP5, GG homozygotes $(N=1$ | 8), A-allele carriers $(N=132)$ without psychiatric morbidity had progressively worse performance on the Stroop color-word task with increasing levels of ELA exposure (Genotype $\times E L A, F=5.14, P=0.007$ ), indicating a $G \times E$ interaction on working memory in early adulthood. In addition, heart rate response to mental stress was diminished overall in $A A / A G$-allele carriers $(F=5.15, P=0.024)$. Diminished working memory and attenuated autonomic responses to stress are both associated with risk for alcoholism and other substance use disorders. The present data suggest that FKBP5 in the GR pathway may be a point of vulnerability to ELA, as seen in this group of non-traumatized young adults. FKBP5 is accordingly a potential target for more extensive studies of the impact of ELA on health and health behaviors in adulthood.

Neuropsychopharmacology (20 I6) 4I, I724-1732; doi:I0.1038/npp.20 I 5.347; published online 3 February 2016
\end{abstract}

\section{INTRODUCTION}

Exposure to stress during critical periods of development has adverse effects on health and health behaviors in adulthood (Dube et al, 2003). There is suggestive evidence that specific genetic polymorphisms may constitute vulnerability pathways, by which early-life adversity (ELA) can contribute to maladaptive adult characteristics (Caspi et al, 2002, 2003). We have recently shown that persons with greater exposure to ELA have (a) diminished physiological stress reactivity (Lovallo et al, 2012a), (b) diminished cognitive performance (Lovallo et al, 2013), and (c) altered regulation of affect (Sorocco et al, 2015), and these phenotypic characteristics

* Correspondence: Dr WR Lovallo, Behavioral Sciences Laboratories, VA Medical Center, 755 Research Parkway, Suite 586, Oklahoma City, OK 73I04, USA, Tel: +I 405456 3124, Fax: + I 405456 I839, E-mail: bill@mindbodyl.org

Received 9 September 2015; revised 23 October 2015; accepted 16 November 2015; accepted article preview online 3 December 2015 may contribute to increased risk-taking and vulnerability to alcohol and other substance use disorders. ELA is much more common in persons with a family history of alcoholism (Lovallo et al, 2013), suggesting the desirability of studies of gene-by-environment $(\mathrm{G} \times \mathrm{E})$ interactions on phenotypic characteristics that contribute to substance abuse risk (Moffitt et al, 2006).

The corticosteroid receptor system is a target for such a $\mathrm{G} \times \mathrm{E}$ analysis. Glucocorticoid and mineralocorticoid receptors (GR and MR) are regulated by acute stress exposure, and their functional status is subject to epigenetic programming by early experience (Meaney, 2010; Meaney et al, 1985). The presence of GR and MR throughout the limbic system and prefrontal cortex (McEwen et al, 1969; Sanchez et al, 2000) suggests that modification of corticosteroid receptor pathways can influence behavioral dispositions, affective states, and cognitive function (Champagne and Meaney, 2001; Lupien et al, 2002; Meaney et al, 2013; Zaharia et al, 1996). 
The FKBP5 protein is a molecular cochaperone that contributes to the functional status of the GR (Zannas and Binder, 2014), thereby influencing how cortisol (CORT) interacts with neurons of the central nervous system (CNS) (Davies et al, 2002). FKPB5 acts together with heat-shock proteins to allow free GR in the cytosol to complex with CORT (Pratt and Toft, 1997) permitting translocation of CORT to the cell nucleus, where it then regulates gene expression (Baxter et al, 1972; Rousseau et al, 1975). CORT exerts at least two seemingly opposing effects on FKPB5 expression and GR functionality: (1) CORT increases FKBP5 expression (Hubler and Scammell, 2004; Jaaskelainen et al, 2011) by demethylating an intronic enhancer region of FKPB5 (Lee et al, 2010) and (2) elevated expression of FKBP5 interferes with the final conformation of the GR supercomplex, diminishing its potential for nuclear translocation and impairing cellular responses to CORT (Binder, 2009). Accordingly, CORT elevation, increased FKBP5 expression, and reduced functionality of the GR constitute a potential pathway through which the environment may exert longterm effects on GR and behavior (Zannas and Binder, 2014).

Modification of the GR pathway in the presence of CORT may occur more readily in persons carrying a specific A-to-G single-nucleotide polymorphism (SNP) of FKBP5, rs9296158, under study here. This SNP is in allelic identity and strong linkage disequilibrium with a functional SNP, rs1360780, located in an intronic enhancer of the FKBP5 gene. The rs1360780 minor allele is more readily demethylated in the presence of CORT than is the major, G allele (Klengel et al, 2013). As such, the A allele of rs9296158 may display greater environmental control of the GR pathway with implications for behavior, as supported by several studies. Childhood abuse predicts increased symptoms of post-traumatic stress disorder in A-allele carriers (Binder et al, 2008). Minor allele carriers diagnosed with major depressive disorder have higher basal CORT output that is resistant to dexamethasone suppression (Binder, 2009; Binder et al, 2004). The rs1360780 minor allele predicts suicidal behavior in adults who were abused in childhood (Roy et al, 2010), and FKBP5 genotypes have different levels of amygdala reactivity to emotional faces (White et al, 2012).

Given that minor-allele carriers of FKBP5 rs1360780, and of the tightly linked rs9296158, may be differentially susceptible to ELA, and considering the presence of GR on structures of the limbic system and prefrontal cortex, the effects of ELA may reasonably include changes in temperament, cognitive function, and stress reactivity (Lovallo, 2013; Lovallo et al, 2012b, 2013; Sorocco et al, 2015). Accordingly, we employed a $\mathrm{G} \times \mathrm{E}$ analysis on data from the OFHP cohort to investigate the interactive effects of ELA and FKBP5 rs9296158.

\section{MATERIALS AND METHODS}

\section{Subjects}

Subjects were healthy young adults participating in the OFHP project, a broad-based study of risk factors for alcoholism (Lovallo et al, 2013). The present analysis includes 252 volunteers who had been genotyped for FKBP5 and had sufficient background data to compute ELA scores. Each subject signed an informed consent form approved by the Institutional Review Board of the University of Oklahoma Health Sciences Center and the VA Medical Center, Oklahoma City, Ok, USA, and was given financial compensation.

Inclusion and exclusion criteria. Subjects were 18- to 30year-old men and women from the community who were in self-reported good health. Prospective volunteers were excluded if they had: a mental age score of $<22$ on the Shipley Institute of Living Scale (John and Rattan, 1992); a history of alcohol or drug dependence; substance abuse within the past 2 months; a positive urine screen for abused drugs (iCup, Instant Technologies, Norfolk, VA) or breathalcohol test on days of testing; a history of Axis I disorder, other than past depression ( $>60$ days), using the Diagnostic and Statistical Manual of Mental disorders, 4th ed. (American_Psychiatric_Association, 1994) based on the CDIS-4 interview (Blouin et al, 1988); had a body mass index of $>30 \mathrm{~kg} / \mathrm{m}^{2}$; needed prescription medications other than hormonal contraceptives; or had a current medical disorder. Women all had negative urine pregnancy tests at the time of testing. Smoking and smokeless tobacco use were not exclusionary.

ELA assessment. ELA was derived from C-DIS-IV items closely similar to adverse life events assessed retrospectively in studies by Caspi et al $(2002,2003)$ as follows: Physical or Sexual Adversity ('Have you ever been mugged or threatened with a weapon?' 'Have you ever experienced a break-in or robbery?' 'Have you ever been raped or sexually assaulted by a relative?' 'Have you ever been raped or sexually assaulted by someone not related to you?') and Emotional Adversity ('Before you were 15, was there a time when you did not live with your biological mother for at least 6 months?' 'Before you were 15, was there a time when you did not live with your biological father for at least 6 months?'). Each person was assigned to an ELA group based on 0 reported adverse event, 1 event, or $>1$ event.

\section{Study Design and Procedure}

Subjects passing an initial telephone contact were screened at the laboratory and then tested on 2 days. The laboratory screening was conducted by a trained interviewer supervised by a licensed clinical psychologist and included: the C-DIS-IV interview, assessment of family history of alcoholism using family history research diagnostic criteria (Andreasen et al, 1977; Lovallo et al, 2013), documentation of the subject's smoking, alcohol and drug use history including the Alcohol Use Disorders Identification Test (AUDIT) (Babor et al, 1992), and completion of a series of cognitive, personality, and temperament scales including: the California Personality Inventory Socialization Scale (CPI-So) (Gough, 1994), Beck Depression Inventory (Beck and Beamesderfer, 1974), Eysenck Personality Inventory (Eysenck and Eysenck, 1964), Tridimensional Personality Questionnaire (Cloninger et al, 1991), and the Shipley Institute of Living Scale, Revised (John and Rattan, 1992).

Subjects visited the laboratory twice more for behavioral and stress testing. The first test day involved a stress 
procedure consisting of public speaking and mental arithmetic, and the second day was a resting control day, as described elsewhere (Sorocco et al, 2006). Laboratory testing on both days also involved cognitive testing and behavioral tasks (Lovallo et al, 2013).

\section{Testing procedures}

Stress procedure. Stress testing lasted $105 \mathrm{~min}$, including a resting baseline in a seated position $(30 \mathrm{~min})$ followed by simulated public speaking $(30 \mathrm{~min})$ and mental arithmetic (15 min) and a 30-min resting recovery period as described elsewhere (Al'Absi et al, 1997; Lovallo et al, 2012a). The resting control day involved sitting for $105 \mathrm{~min}$ while reading and watching nature videos. Heart rate was monitored every 2 min along with blood pressure measurements taken on both days using an automated monitor (Critikon, Dinamap). Saliva samples for cortisol determination were collected using the Salivette device (Sarstedt, Newton, NC, USA) at 10 times across each test day, including: at home upon awakening and at bedtime, and 8 times in the lab, including twice during the stress protocol and twice during recovery (Lovallo et al, 2010a). Salivettes were centrifuged at 4200 r.p.m. for $20 \mathrm{~min}$, and saliva was stored at $-70^{\circ} \mathrm{C}$. Assays were conducted by Salimetrics (State College, PA, USA) where the saliva-free cortisol concentrations were quantified using a competitive enzymatic immunoassay (Salimetrics, 2015). The assay has a sensitivity of $<.083 \mu \mathrm{g} / \mathrm{dl}$ and an interassay coefficient of variation of $<6.42 \%$. Stress responses were computed as the difference in respective values obtained during the stress day compared with the corresponding values on the resting control day and then averaged to provide a single reactivity score, as discussed previously (Al'Absi et al, 1997; Lovallo et al, 2010a).

Cognitive and behavioral tasks. The Stroop ColorWord Test, Dodrill's version, consists of 176 repetitions of the color words 'red, orange, green, and blue,' presented in a random order with each word printed in a discrepant ink color (eg, the word 'red' printed in blue ink). The subject recites the list aloud two times, first reading the printed words and next reporting the ink colors. Time is recorded during each reading, and an interference score is calculated as the difference between the time to read the ink colors and time to read the words (Salinsky et al, 2002; Stroop, 1935). The Tridimensional Personality Questionnaire (Cloninger, 1987) contains three subscales, Novelty Seeking, Harm Avoidance, and Reward Dependence, purported to assess temperament underlying motivations to obtain rewards and avoid punishments in relation to stimuli such as alcohol and recreational drugs (Cloninger et al, 1991).

Additional cognitive and behavioral tasks included: the Iowa Gambling Task (Bechara et al, 1994), the Balloon Analogue Response Task (Lejuez et al, 2002), a Go-NoGo reaction time task (Saunders et al, 2008), the ultimatum game (Sanfey et al, 2003), and a delay discounting task (Acheson et al, 2011).

\section{Genotyping}

Subjects provided a saliva sample by passive drool into an Oragene collection and preservation kit (DNA Genotek,
Kanata, Ontario, Canada). DNA samples were genotyped with the Illumina OmniExpress array using standard protocols. Samples with call rates below 95\% were excluded, and randomly selected samples showed an average reproducibility of $99.998 \%$. The genotype completion rate was 0.993 (using a cutoff of 0.95 call rate). The OmniExpress array does not contain the rs1360780 SNP for FKBP5, although the linked tag SNP, rs9296158, is available and is in HardyWeinberg equilibrium, and so the latter was used in the present analysis. Of the 252 samples, we were able to impute 241 rs1360780 genotypes with an accuracy of 0.974 using IMPUTE2. Only three genotypes differed between rs 1360780 and rs9296158; and therefore, the latter SNP was used in the present analysis because of the larger sample size.

Assessment of population stratification using ancestry informative markers (AIMS). A panel of 2491 SNPs from the Illumina OmniExpress array was selected as AIMS based on the following criteria: (1) large differences in the reference allele frequency of pairwise SNPs from the HapMap Project between African, Chinese, and European populations; (2) mapping on different chromosomes or in different regions of the same chromosome; and (3) shared by both Illumina Human Hap550v3 and HumanOmniExpress-12v1 array. Individual ethnic factor scores corresponding to geographical regions: Africa, Europe, Middle East, Central Asia, Far East Asia, Oceania, and America, were estimated using STRUCTURE v2.3 software and using a known set of 1051 subjects representing 51 worldwide populations (CEPH population) as a reference (http://www.cephb.fr/en/hgdp_panel. php). The data set was predominantly Caucasian. The mean (SD) and median European ancestry of the sample were 0.89 $(0.19)$ and 0.95 . Twenty participants had EU ancestry $\%<0.50$, 16 of African ancestry, and 4 of Native American ancestry.

\section{Data Analysis}

In accordance with our previous findings on the impact of ELA, data analysis included the predictor variables, Genotype and ELA, and five functional families of dependent variables representing: (a) stress reactivity including CORT and heart rate (HR) change to stress, (b) cognition (Stroop Interference and Shipley Mental Age scores), (c) affect regulation and temperament (scores on the Eysenck neuroticism scale, Beck Depression Inventory, Tridimensional Personality Questionnaire, and CPI-So scale), (d) behavioral impulsivity (BART, Iowa Gambling Task, GoNoGo reaction time task, ultimatum game, and delay discounting), and (e) substance use and dietary practice (drinking variables, drug experimentation, smoking, and BMI). The families of variables were organized by function in a heuristic model conceptualizing how ELA could have a differential impact on vulnerable persons, resulting in enhanced risk of alcohol and other substance use disorders (Lovallo, 2013).

Because of small sample sizes, we combined data from the AA homozygotes $(N=25)$ with the AG heterozygotes $(N=116)$ for the analyses. (Data are displayed for the AA, AG, and GG genotypes in Supplementary information.) The data were subjected to analyses of variance including: Genotype (AA/AG, GG), ELA $(0,1,>1)$, and the G $\times$ ELA interaction term. Type III sums of squares were used to 
ensure independence of individual $\mathrm{F}$ ratios. In preliminary analyses we examined the impact of ancestry by comparing persons with Caucasian vs non-Caucasian AIMS in the analytic model, and we also included the separate European, African, Far East Asian, Oceanian, and American ancestry scores as covariates. These preliminary analyses did not change the results, and ancestry was not considered further. Tests were considered as statistically significant if $P<0.05$. Analyses were conducted using SAS software 9.2 (Copyright, SAS Institute, Cary, NC, USA).

\section{RESULTS}

Demographics and group descriptive data for the FKBP5 Genotype $(\mathrm{AA} / \mathrm{AG}, \mathrm{GG}) \times \operatorname{ELA}(0,1,>1)$ groups are shown in Table 1 . No significant $G \times$ ELA interactions were found for age, SES, or years of education, although persons with higher ELA scores had lower SES and fewer years of education, and were more likely to be from a family with a history of alcoholism, as reported previously (Lovallo, 2013). Persons in the present sample are considered to be nontraumatized since selection criteria excluded persons meeting diagnostic criteria for post-traumatic stress disorder or current major depression.

\section{G $\times$ ELA Analyses}

Cognitive function. Interference scores on the Stroop task showed a significant ELA $\times$ Genotype interaction, $\mathrm{F}=5.14$, $P=0.007$, partial eta ${ }^{2}=0.04$, in which AA/AG carriers had progressively poorer performance with 0,1 , and $>1$ ELA events. No effect of ELA appeared in GG homozygotes (Figure 1, top). We also observed significant main effects of ELA, $\mathrm{F}=3.45, P=0.03$, partial eta ${ }^{2}=0.03$, and Genotype, $\mathrm{F}=6.66, P=0.01$, partial eta ${ }^{2}=0.026$, with poorer performance occurring with greater ELA exposure and in AA/AG carriers. No significant effects were seen in Shipley Institute of Living Scale mental age scores, as shown in Table 1.

Stress reactivity. As shown in Figure 1, middle panel, HR response to stress was significantly lower in persons carrying the minor FKBP5 allele (AA/AG) relative to GG homozygotes, $\mathrm{F}=5.15, P=0.024$, partial eta $^{2}=0.021$. Although the ELA $\times$ Genotype interaction was not significant, $\mathrm{F}<1.0$, A-allele carriers appear to show a diminishing HR response as a function of greater ELA exposure. Cortisol data showed no ELA $\times$ Genotype effects for baseline values or stress responses, as shown in Table 1. These findings were not influenced by subjective responses to the stressors, as the $\mathrm{AA} / \mathrm{AG}$ and GG genotypes did not differ in their reports of subjective activation and distress on the rest day or changes from rest to stress day.

Affect and temperament. We observed a modest main effect of Genotype on the TPQ Reward Dependence scores, $\mathrm{F}=4.01, P=0.046$, partial eta ${ }^{2}=0.016$, such that minor allele carriers had higher scores on this scale than G-allele homozygotes, as shown in Figure 1, bottom, and Table 1. No genotype differences were seen in any other variable in this category as shown in Table 1.
Behavioral impulsivity. None of the variables included in the behavioral impulsivity cluster showed a significant main effect of genotype, ELA, or a G $\times$ ELA interaction, and these are not described further.

\section{DISCUSSION}

We examined healthy young adults for a $\mathrm{G} \times \mathrm{E}$ relationship between ELA exposure and the rs9296158 SNP as a surrogate for the functional SNP, rs136078, on the FKBP5 gene. FKBP5 is a molecular cochaperone that has a role in the functional status of the GR. Its place in the GR pathway and its consequent interactions with CORT signaling and stress mechanisms make it a potential target for extensive study of environmental impacts on behavior. Because GR function is relatively disrupted in A-allele carriers, we predicted that behavioral and physiological functions associated with the GR system could be modified differentially by ELA in AA/ AG relative to GG carriers. Earlier analyses of the OFHP study population have shown a significant overall impact of ELA on stress reactivity, cognitive function, temperament, and behavior (Lovallo, 2013; Lovallo et al, 2012a; Sorocco et al, 2015). The present analysis extends these findings by showing a differential vulnerability to ELA in FKBP5 A-allele carriers that is lacking in GG homozygotes. Stroop task performance was progressively worse in A-allele carriers exposed to increasing amounts of ELA, with no such effect in GG homozygotes. This finding points to a possible $\mathrm{G} \times \mathrm{E}$ effect on working memory. We also observed significant FKBP5 genotype main effects on HR response to stress and, to a more limited degree, on the temperament characteristic of reward dependence, both of which showed a greater impact of ELA among AA/AG carriers. These findings bear comparison to current research on $\mathrm{G} \times \mathrm{E}$ effects involving FKBP5 alleles, and they suggest avenues for future study.

The importance of the GR pathway for behavioral regulation is consistent with the presence of GR in the limbic system and prefrontal cortex as seen in animal models (McEwen et al, 1968; Sanchez et al, 2000). Acute administration of hydrocortisone to human volunteers at rest leads to rapid changes in amygdala and hippocampal activation, seen using fMRI (Lovallo et al, 2010b). Hydrocortisone taken after exposure to emotional photographs aids in establishment of long-term declarative memories (Buchanan and Lovallo, 2001). Corticosteroids also have acute and long-term effects on working memory (Al'Absi et al, 2002; Oei et al, 2009; Terfehr et al, 2011b). Patients with CORT excess because of Cushing's syndrome and a deficit due to Addison's disease both show cognitive and emotional disturbances, involving disruption of GR-mediated functions of the prefrontal cortex and limbic systems (Anglin et al, 2006; Starkman et al, 1981, 1992; Tytherleigh et al, 2004), and these deficits resolve with successful treatment (Schultebraucks et al, 2015; Starkman et al, 1999). The importance of GR pathways in registering the effects of stress is seen in studies of psychiatric morbidity indicating that FKBP5 A-allele carriers are vulnerable to a history of traumatic stress exposure that is associated with risk for depression (Binder et al, 2004) and anxiety disorders (Binder, 2009), including posttraumatic stress disorder (Binder et al, 2008). We have previously identified four 
Table I Demographics and Outcome Variables for FKBP5 and ELA Groups

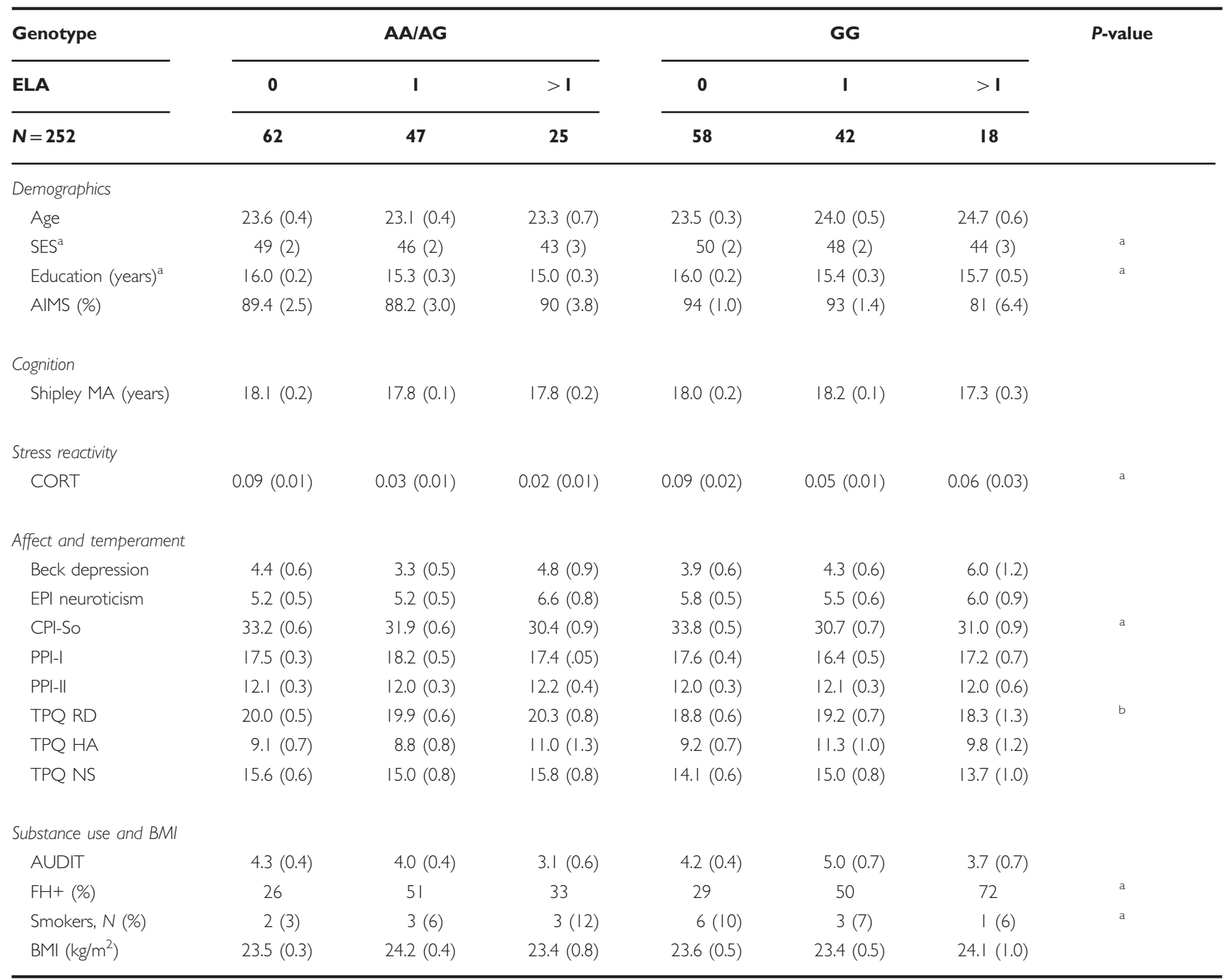

Abbreviations: AIMS, Ancestry Informative Markers (\% with European ancestry markers); AUDIT, Alcohol Use Disorders Information Test; BMI, body mass index; CORT, cortisol response to stress; CPI-So, California Personality Inventory Socialization Scale; ELA, Early-Life Adverse experience; FH+, Positive parental history for alcohol use disorder; HA, Harm Avoidance; MA, Shipley mental age score; NS, novelty seeking; PPI, Psychopathic Personality Inventory (I= core psychopathy, II = disinhibition); RD, Reward Dependence; SES, socioeconomic status; TPO, Tridimensional Personality Questionnaire.

Entries show mean $( \pm$ SEM) unless otherwise noted. No significant ELA $\times$ Genotype interactions were found for any listed variable.

${ }^{\mathrm{a} E L A}, P<0.05$.

${ }^{\mathrm{b}}$ Genotype, $P<0.05$.

families of adult outcomes resulting from ELA exposure: cognitive function, stress reactivity, personality and temperament, and behavioral impulsivity, and have incorporated these into a heuristic model of ELA and risk for alcohol and other substance use disorders (Lovallo, 2013). The current results extend this analysis to show enhanced vulnerability to ELA in healthy, non-traumatized young adults who carry the FKBP5 A allele.

The present Stroop performance data suggest that working memory processes are subject to a $\mathrm{G} \times \mathrm{E}$ interaction as a function ELA and FKBP5 genotype. Stroop performance assesses working memory, executive processes in particular (Smith and Jonides, 1997, 1999), and these in turn are influenced by the functional status of the dorsolateral prefrontal cortex, the anterior cingulate gyrus (Friedman and Goldman-Rakic, 1994; Goldman-Rakic, 1998), and the temporoparietal association cortex (Acheson et al, 2014; Silveri et al, 2011). Given the distribution of GR in prefrontal cortex, modification of the GR pathway by the A allele of FKBP5 is a particularly useful target for the study of $\mathrm{G} \times \mathrm{E}$ effects on behavior and psychological characteristics (Bogdan et al, 2015). Variants of the GR gene are associated with altered working memory performance (Kumsta et al, 2010). Healthy subjects carrying the rare variant allele of FKBP5, rs1360780, closely linked to the rs9296158 SNP used here, had greater attentional biasing and levels of hippocampal 

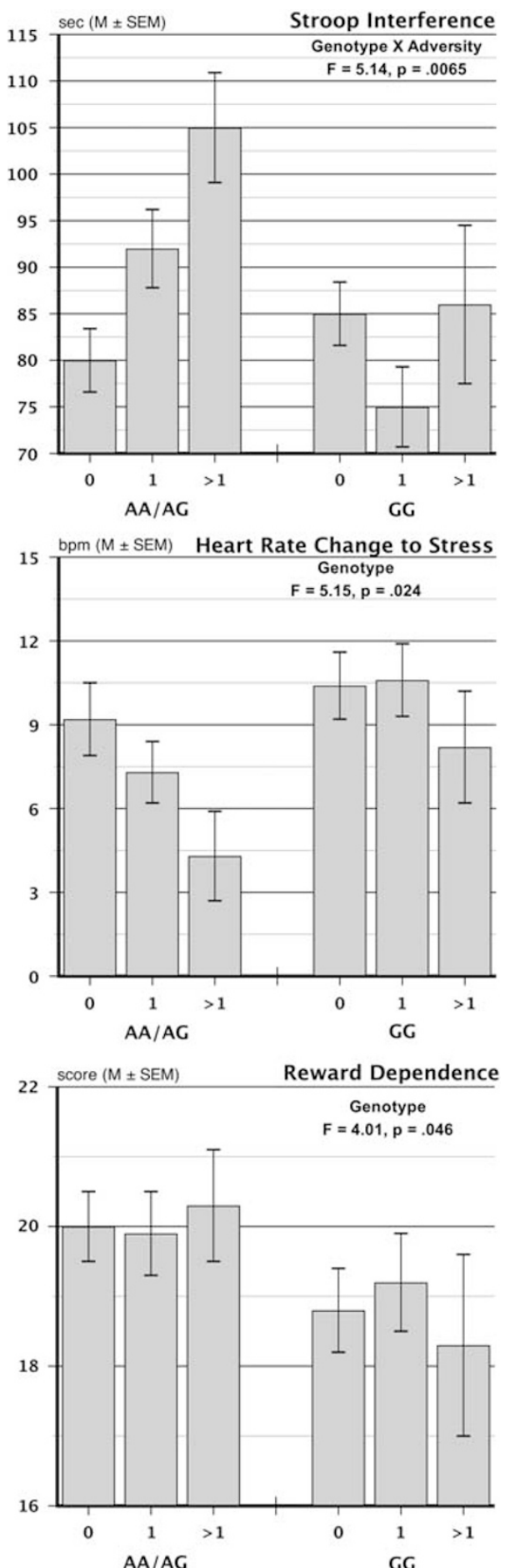

Figure I Effects of exposure to early-life adverse events in childhood and adolescence $(0,1$, or $>$ I events) in persons carrying AA or AG alleles of the gene for the molecular cochaperone, FKBP5 vs GG carriers. Top panel: Interference scores on the Stroop color-word test. Middle panel: Increase in $H R$ from rest during exposure to a combined mental arithmetic and public speaking stressor. Bottom panel: Scores on the Reward Dependence scale of the Tridimensional Personality Questionnaire.

activation to threat signals in a dot-probe task (Fani et al, 2013). FKBP5 genotypes and ELA showed a $\mathrm{G} \times \mathrm{E}$ effect on amygdala responses to emotional faces in adults ( $\mathrm{Holz}$ et al, 2015) and amygdala volumes in children (Pagliaccio et al,
2014), as reviewed elsewhere (Bogdan et al, 2015). Other research shows that reduced working memory capacity is associated with elevated risk for alcohol and other substance use disorders (Cservenka et al, 2012; Desmond et al, 2003; Finn et al, 2002; Lovallo et al, 2006). The present findings and work just cited suggest the value of more intensive study of working memory and its interactions with emotional responsivity in relation to ELA in FKBP5 AA/AG carriers.

In examining physiological responses to behavioral stress, we observed a diminished HR response among FKBP5 AA/ AG allele carriers, but we saw no corresponding difference in CORT reactivity. The diminished $\mathrm{HR}$ response to our mental stress protocol among A-allele carriers was accompanied by a non-significant tendency toward progressively smaller responses as a function of increasing ELA. The HR data therefore support reduction in autonomic reactivity to stress in carriers of the A allele of FKBP5, but a more complete understanding of a differential vulnerability to ELA will require a larger sample size, as being currently acquired in the OFHP. Additional studies should also address whether the diminished HR reactivity observed here is associated with diminished limbic system outputs through the hypothalamus and brainstem pathways to the heart. Diminished HR responses to stress are seen in abstinent alcoholic patients (Panknin et al, 2002) and in persons at elevated risk for alcohol and other substance use disorders (Lovallo, 2013). These results, and the potential association of blunted stress reactivity with substance use disorders, suggest the value of studying a broader range of autonomically mediated stress responses in relation to FKBP5 allele status and exposure to ELA.

In contrast to our HR findings, we observed no impact of FKBP5 genotype on CORT levels or stress responses, although CORT reactivity was progressively diminished in response to ELA exposure levels (Lovallo et al, 2012a). Although CORT results might be expected to parallel HR findings, this is not a necessary outcome. If ELA acts by way of epigenetic changes to FKBP5 expression, then these effects may vary according to both the person-environment interaction and the specific cell types found in different brain regions (see Klengel and Binder, 2015 for a review). For example, demethylation of the FKBP5 enhancer region following dexamethasone occurs in hippocampal dentate gyrus but not in other hippocampal tissues (Yang et al, 2012). Other data suggest that the effects of FKBP5 on CORT regulation may be confined to depressed patients (Binder, 2009; Menke et al, 2013), but not in healthy controls (Menke et al, 2013). Our cohort consists of healthy individuals whose affective responses to the environment may accordingly differ from persons with clinical depression. Similarly, while acute administration of hydrocortisone alters memory performance in healthy controls, it may not do so in patients with major depressive disorder (Terfehr et al, 2011a), and there are several non-FKBP5 candidate mechanisms that may contribute to GR modifications specific to depression (Bet et al, 2009; Derijk and de Kloet, 2008; Kumsta et al, 2009; Pariante, 2004; van Rossum et al, 2006; van West et al, 2006).

In addition to the lack of cortisol effects, we also saw no effects of FKBP5 on a range of cognitive, psychological, and behavioral measures under study here (Table 1) other than reward dependence. This lack of uniformity of $G \times E$ effects 
across this range of tasks and self-report instruments may be attributable to differences in the sensitivity of the different measures, and ELA effects may not be reflected equally in all brain regions and on their associated functions. In this case, animal models can provide useful guides for interpreting human data, but predictions in the case of individual cognitive and behavioral tasks are premature at present.

The present findings are subject to several limitations. The sample of AA carriers is currently small $(N=25)$, limiting our analysis of potential gene-dose effects. The Stroop interference data represent a limited slice of possible working memory processes, and future work would benefit from intensive study of other tasks to probe-specific working memory components. The HR results presented here point to a possible ELA effect in A-allele carriers, although achieving a significant $\mathrm{G} \times \mathrm{E}$ interaction may require a larger sample size. Although we tested a number of dependent variables, we did not correct for multiple statistical tests. Our reasons were that: (1) we examined different families of phenotypic variables, (2) our earlier ELA findings supported the $\mathrm{G} \times \mathrm{E}$ approach used here, and (3) the lack of existing data in relation to the reasonable ELA-FKBP5 call for exploratory analyses leading to more hypothesis-driven approaches in future studies. We therefore consider the present findings to be exploratory in nature.

Healthy young adult carriers of the FKBP5 A allele showed progressively diminished working memory performance following greater levels of ELA, indicating vulnerability to environmental stress in carriers this genotype (Klengel et al, 2013). Under this mechanism, A-allele carriers, possibly being exposed to elevated CORT accompanying the stress of ELA, may have shown upregulation of FKBP5 expression and reprogramming of GR pathways, leading to behavioral effects persisting into early adulthood. As our strongest finding involved working memory, we conclude that ELA may have affected the prefrontal cortex and, by extension, its interactions with the limbic system.

\section{CONCLUSION}

The long-term effects of stress during childhood and adolescent development may be reflected in the functional status of the GR pathway, and these effects may be exaggerated in persons inheriting the minor, rs9296158 allele of the molecular cochaperone, FKBP5. Early-life stress was reflected in A-allele carriers as diminished cognitive function and blunted stress reactivity. These functional changes may have clinical consequences as diminished working memory capacity and blunted cardiac responses to stress are associated with disinhibitory behavioral characteristics, delinquency, and risk for alcoholism (Gao et al, 2010; Lovallo, 2013; Panknin et al, 2002). Functional variants of FKBP5 are a possible target for further study in relation to ELA and its contribution to poor health behaviors in adulthood, including risk for alcohol and other substance use disorders.

\section{FUNDING AND DISCLOSURE}

The authors declare no conflict of interest.

\section{ACKNOWLEDGMENTS}

The content is solely the view of the authors and does not necessarily represent the official view of the National Institutes of Health or the Department of Veterans Affairs. Supported by the Department of Veterans Affairs Medical Research Service; NIH Grants, NIAAA R01AA019691 and R01 AA012207, and the NIAAA Intramural Research Program.

\section{REFERENCES}

Acheson A, Franklin C, Cohoon AJ, Glahn DC, Fox PT, Lovallo WR (2014). Anomalous temporoparietal activity in individuals with a family history of alcoholism: studies from the Oklahoma Family Health Patterns Project. Alcohol Clin Exp Res 38: 1639-1645.

Acheson A, Vincent AS, Sorocco KH, Lovallo WR (2011). Greater discounting of delayed rewards in young adults with family histories of alcohol and drug use disorders: studies from the Oklahoma family health patterns project. Alcohol Clin Exp Res 35: 1607-1613.

Al'Absi M, Bongard S, Buchanan T, Pincomb GA, Licinio J, Lovallo WR (1997). Cardiovascular and neuroendocrine adjustment to public speaking and mental arithmetic stressors. Psychophysiology 34: 266-275.

Al'Absi M, Hugdahl K, Lovallo WR (2002). Adrenocortical stress responses and altered working memory performance. Psychophysiology 39: 95-99.

American_Psychiatric_Association (1994). Diagnostic and Statistical Manual of Mental Disorders, 4th (text rev.) edn. American Psychiatric Association: Washington, DC, USA.

Andreasen NC, Endicott J, Spitzer RL, Winokur G (1977). The family history method using diagnostic criteria. Reliability and validity. Arch Gen Psychiatry 34: 1229-1235.

Anglin RE, Rosebush PI, Mazurek MF (2006). The neuropsychiatric profile of Addison's disease: revisiting a forgotten phenomenon. J Neuropsychiatry Clin Neurosci 18: 450-459.

Babor TF, De La Fuente JR, Saunders J, Grant M (1992). AUDIT: The Alcohol Use Disorders Identification Test: Guidelines for Use in Primary Health Care. World Health Organization: Geneva, Switzerland.

Baxter JD, Rousseau GG, Benson MC, Garcea RL, Ito J, Tomkins GM (1972). Role of DNA and specific cytoplasmic receptors in glucocorticoid action. Proc Natl Acad Sci USA 69: 1892-1896.

Bechara A, Damasio AR, Damasio H, Anderson SW (1994). Insensitivity to future consequences following damage to human prefrontal cortex. Cognition 50: 7-15.

Beck AT, Beamesderfer A (1974). Assessment of depression: the depression inventory. Mod Probl Pharmacopsychiatry 7: 151-169.

Bet PM, Penninx BW, Bochdanovits Z, Uitterlinden AG, Beekman AT, van Schoor NM et al (2009). Glucocorticoid receptor gene polymorphisms and childhood adversity are associated with depression: New evidence for a gene-environment interaction. Am $J$ Med Genet B Neuropsychiatr Genet 150B: 660-669.

Binder EB (2009). The role of FKBP5, a co-chaperone of the glucocorticoid receptor in the pathogenesis and therapy of affective and anxiety disorders. Psychoneuroendocrinology 34 (Suppl 1): S186-S195.

Binder EB, Bradley RG, Liu W, Epstein MP, Deveau TC, Mercer KB et al (2008). Association of FKBP5 polymorphisms and childhood abuse with risk of posttraumatic stress disorder symptoms in adults. JAMA 299: 1291-1305.

Binder EB, Salyakina D, Lichtner P, Wochnik GM, Ising M, Putz B et al (2004). Polymorphisms in FKBP5 are associated with increased recurrence of depressive episodes and rapid response to antidepressant treatment. Nat Genet 36: 1319-1325. 
Blouin AG, Perez EL, Blouin JH (1988). Computerized administration of the Diagnostic Interview Schedule. Psychiatry Res 23: 335-344.

Bogdan R, Pagliaccio D, Baranger DA, Hariri AR (2016). Genetic moderation of stress effects on corticolimbic circuitry. Neuropsychopharmacology 41: 275-296.

Buchanan TW, Lovallo WR (2001). Enhanced memory for emotional material following stress-level cortisol treatment in humans. Psychoneuroendocrinology 26: 307-317.

Caspi A, McClay J, Moffitt TE, Mill J, Martin J, Craig IW et al (2002). Role of genotype in the cycle of violence in maltreated children. Science 297: 851-854.

Caspi A, Sugden K, Moffitt TE, Taylor A, Craig IW, Harrington H et al (2003). Influence of life stress on depression: moderation by a polymorphism in the 5-HTT gene. Science 301: 386-389.

Champagne F, Meaney MJ (2001). Like mother, like daughter: evidence for non-genomic transmission of parental behavior and stress responsivity. Prog Brain Res 133: 287-302.

Cloninger CR (1987). Neurogenetic adaptive mechanisms in alcoholism. Science 236: 410-416.

Cloninger CR, Przybeck TR, Svrakic DM (1991). The tridimensional personality questionnaire: US normative data. Psychol Rep 69(3 Pt 1): 1047-1057.

Cservenka A, Herting MM, Nagel BJ (2012). Atypical frontal lobe activity during verbal working memory in youth with a family history of alcoholism. Drug Alcohol Depend 123: 98-104.

Davies TH, Ning YM, Sanchez ER (2002). A new first step in activation of steroid receptors: hormone-induced switching of FKBP51 and FKBP52 immunophilins. J Biol Chem 277: $4597-4600$.

Derijk RH, de Kloet ER (2008). Corticosteroid receptor polymorphisms: determinants of vulnerability and resilience. Eur $J$ Pharmacol 583: 303-311.

Desmond JE, Chen SH, DeRosa E, Pryor MR, Pfefferbaum A, Sullivan EV (2003). Increased frontocerebellar activation in alcoholics during verbal working memory: an fMRI study. Neuroimage 19: 1510-1520.

Dube SR, Felitti VJ, Dong M, Giles WH, Anda RF (2003). The impact of adverse childhood experiences on health problems: evidence from four birth cohorts dating back to 1900. Prev Med 37: $268-277$.

Eysenck SB, Eysenck HJ (1964). An improved short questionnaire for the measurement of extraversion and neuroticism. Life Sci 305: 1103-1109.

Fani N, Gutman D, Tone EB, Almli L, Mercer KB, Davis J et al (2013). FKBP5 and attention bias for threat: associations with hippocampal function and shape. JAMA Psychiatry 70: 392-400.

Finn PR, Mazas CA, Justus AN, Steinmetz J (2002). Early-onset alcoholism with conduct disorder: go/no go learning deficits, working memory capacity, and personality. Alcohol Clin Exp Res 26: 186-206.

Friedman HR, Goldman-Rakic PS (1994). Coactivation of prefrontal cortex and inferior parietal cortex in working memory tasks revealed by 2DG functional mapping in the rhesus monkey. $J$ Neurosci 14(5 Pt 1): 2775-2788.

Gao Y, Raine A, Venables PH, Dawson ME, Mednick SA (2010). Association of poor childhood fear conditioning and adult crime. Am J Psychiatry 167: 56-60.

Goldman-Rakic PS (1998). Topography of cognition: Parallel distributed networks in primate association cortex. Annu Rev Neurosci 11: 137-156.

Gough HG (1994). Theory, development, and interpretation of the CPI socialization scale. Psychol Rep 75(1 Pt 2): 651-700.

Holz NE, Buchmann AF, Boecker R, Blomeyer D, Baumeister S, Wolf I et al (2015). Role of FKBP5 in emotion processing: results on amygdala activity, connectivity and volume. Brain Struct Funct 220: $1355-1368$.

Hubler TR, Scammell JG (2004). Intronic hormone response elements mediate regulation of FKBP5 by progestins and glucocorticoids. Cell Stress Chaperones 9: 243-252.

Jaaskelainen T, Makkonen H, Palvimo JJ (2011). Steroid upregulation of FKBP51 and its role in hormone signaling. Curr Opin Pharmacol 11: 326-331.

John KR, Rattan G (1992). Test Critiques. In: Keyser DJ, Sweetland RC (eds). Shipley Institute of Living Scale-Revised, Vol IX. Pro-Ed: Austin, TX, pp 490-495.

Klengel T, Binder EB (2015). FKBP5 allele-specific epigenetic modification in gene by environment interaction. Neuropsychopharmacology 40: 244-246.

Klengel T, Mehta D, Anacker C, Rex-Haffner M, Pruessner JC, Pariante CM et al (2013). Allele-specific FKBP5 DNA demethylation mediates gene-childhood trauma interactions. Nature neuroscience 16: 33-41.

Kumsta R, Entringer S, Koper JW, van Rossum EF, Hellhammer DH, Wust S (2010). Working memory performance is associated with common glucocorticoid receptor gene polymorphisms. Neuropsychobiology 61: 49-56.

Kumsta R, Moser D, Streit F, Koper JW, Meyer J, Wust S (2009). Characterization of a glucocorticoid receptor gene (GR, NR3C1) promoter polymorphism reveals functionality and extends a haplotype with putative clinical relevance. Am J Med Genet B Neuropsychiatr Genet 150B: 476-482.

Lee RS, Tamashiro KL, Yang X, Purcell RH, Harvey A, Willour VL et al (2010). Chronic corticosterone exposure increases expression and decreases deoxyribonucleic acid methylation of Fkbp5 in mice. Endocrinology 151: 4332-4343.

Lejuez CW, Read JP, Kahler CW, Richards JB, Ramsey SE, Stuart GL et al (2002). Evaluation of a behavioral measure of risk taking: the Balloon Analogue Risk Task (BART). J Exp Psychol Appl 8: 75-84.

Lovallo WR (2013). Early life adversity reduces stress reactivity and enhances impulsive behavior: implications for health behaviors. Int J Psychophysiol 90: 8-16.

Lovallo WR, Farag NH, Sorocco KH, Acheson A, Cohoon AJ, Vincent AS (2013). Early life adversity contributes to impaired cognition and impulsive behavior: studies from the Oklahoma Family Health Patterns Project. Alcohol Clin Exp Res 37: 616-623.

Lovallo WR, Farag NH, Sorocco KH, Cohoon AJ, Vincent AS (2012a). Lifetime adversity leads to blunted stress axis reactivity: studies from the Oklahoma family health patterns project. Biol Psychiatry 71: 344-349.

Lovallo WR, Farag NH, Sorocco KH, Cohoon AJ, Vincent AS (2012b). Lifetime adversity leads to blunted stress axis reactivity: studies from the Oklahoma Family Health Patterns Project. Biol Psychiatry 71: 344-349.

Lovallo WR, Farag NH, Vincent AS (2010a). Use of a resting control day in measuring the cortisol response to mental stress: diurnal patterns, time of day, and gender effects. Psychoneuroendocrinology 35: 1253-1258.

Lovallo WR, Robinson JL, Glahn DC, Fox PT (2010b). Acute effects of hydrocortisone on the human brain: an fMRI study. Psychoneuroendocrinology 35: 15-20.

Lovallo WR, Yechiam E, Sorocco KH, Vincent AS, Collins FL (2006). Working memory and decision-making biases in young adults with a family history of alcoholism: studies from the Oklahoma family health patterns project. Alcohol Clin Exp Res 30: 763-773.

Lupien SJ, Wilkinson CW, Briere S, Menard C, Ng Ying Kin NM, Nair NP (2002). The modulatory effects of corticosteroids on cognition: studies in young human populations. Psychoneuroendocrinology 27: 401-416.

McEwen BS, Weiss JM, Schwartz LS (1968). Selective retention of corticosterone by limbic structures in rat brain. Nature 220: 911-912. 
McEwen BS, Weiss JM, Schwartz LS (1969). Uptake of corticosterone by rat brain and its concentration by certain limbic structures. Brain Res 16: 227-241.

Meaney MJ (2010). Epigenetics and the biological definition of gene x environment interactions. Child Dev 81: 41-79.

Meaney MJ, Aitken DH, Bodnoff SR, Iny LJ, Sapolsky RM (1985). The effects of postnatal handling on the development of the glucocorticoid receptor systems and stress recovery in the rat. Prog Neuropsychopharmacol Biol Psychiatry 9: 731-734.

Meaney MJ, Aitken DH, Bodnoff SR, Iny LJ, Tatarewicz JE, Sapolsky RM (2013). Early postnatal handling alters glucocorticoid receptor concentrations in selected brain regions. Behav Neurosci 127: 637-641.

Menke A, Klengel T, Rubel J, Bruckl T, Pfister H, Lucae S et al (2013). Genetic variation in FKBP5 associated with the extent of stress hormone dysregulation in major depression. Genes Brain Behav 12: 289-296.

Moffitt TE, Caspi A, Rutter M (2006). Measured gene-environment interactions in psychopathology. Perspect Psychol Sci 1: 5-27.

Oei NY, Tollenaar MS, Spinhoven P, Elzinga BM (2009). Hydrocortisone reduces emotional distracter interference in working memory. Psychoneuroendocrinology 34: 1284-1293.

Pagliaccio D, Luby JL, Bogdan R, Agrawal A, Gaffrey MS, Belden AC et al (2014). Stress-system genes and life stress predict cortisol levels and amygdala and hippocampal volumes in children. Neuropsychopharmacology 39: 1245-1253.

Panknin TL, Dickensheets SL, Nixon SJ, Lovallo WR (2002). Attenuated heart rate responses to public speaking in individuals with alcohol dependence. Alcohol Clin Exp Res 26: 841-847.

Pariante CM (2004). Glucocorticoid receptor function in vitro in patients with major depression. Stress 7: 209-219.

Pratt WB, Toft DO (1997). Steroid receptor interactions with heat shock protein and immunophilin chaperones. Endocr Rev 18: 306-360.

Rousseau GG, Higgins SJ, Baxter JD, Gelfand D, Tomkins GM (1975). Binding of glucocorticoid receptors to DNA. J Biol Chem 250: 6015-6021.

Roy A, Gorodetsky E, Yuan Q, Goldman D, Enoch MA (2010). Interaction of FKBP5, a stress-related gene, with childhood trauma increases the risk for attempting suicide. Neuropsychopharmacology 35: 1674-1683.

Salimetrics (2015). High sensitivity salivary cortisol enzyme immunoassay kit. https://www.salimetrics.com/assay-kit/cortisol-salivary-elisa-eia-kit.

Salinsky MC, Binder LM, Oken BS, Storzbach D, Aron CR, Dodrill CB (2002). Effects of gabapentin and carbamazepine on the EEG and cognition in healthy volunteers. Epilepsia 43: 482-490.

Sanchez MM, Young LJ, Plotsky PM, Insel TR (2000). Distribution of corticosteroid receptors in the rhesus brain: relative absence of glucocorticoid receptors in the hippocampal formation. J Neurosci 20: $4657-4668$.

Sanfey AG, Rilling JK, Aronson JA, Nystrom LE, Cohen JD (2003). The neural basis of economic decision-making in the Ultimatum Game. Science 300: 1755-1758.

Saunders B, Farag N, Vincent AS, Collins FL Jr, Sorocco KH, Lovallo WR (2008). Impulsive errors on a Go-NoGo reaction time task: disinhibitory traits in relation to a family history of alcoholism. Alcohol Clin Exp Res 32: 888-894.

Schultebraucks K, Wingenfeld K, Heimes J, Quinkler M, Otte C (2015). Cognitive function in patients with primary adrenal insufficiency (Addison's disease). Psychoneuroendocrinology 55: $1-7$.

Silveri MM, Rogowska J, McCaffrey A, Yurgelun-Todd DA (2011). Adolescents at risk for alcohol abuse demonstrate altered frontal lobe activation during Stroop performance. Alcohol Clin Exp Res 35: $218-228$

Smith EE, Jonides J (1997). Working memory: a view from neuroimaging. Cognit Psychol 33: 5-42.

Smith EE, Jonides J (1999). Storage and executive processes in the frontal lobes. Science 283: 1657-1661.

Sorocco KH, Carnes NC, Cohoon AJ, Vincent AS, Lovallo WR (2015). Risk factors for alcoholism in the Oklahoma Family Health Patterns project: impact of early life adversity and family history on affect regulation and personality. Drug Alcohol Depend 150: 38-45.

Sorocco KH, Lovallo WR, Vincent AS, Collins FL (2006). Blunted hypothalamic-pituitary-adrenocortical axis responsivity to stress in persons with a family history of alcoholism. Int J Psychophysiol 59: $210-217$.

Starkman MN, Gebarski SS, Berent S, Schteingart DE (1992). Hippocampal formation volume, memory dysfunction, and cortisol levels in patients with Cushing's syndrome. Biol Psychiatry 32: 756-765.

Starkman MN, Giordani B, Gebarski SS, Berent S, Schork MA, Schteingart DE (1999). Decrease in cortisol reverses human hippocampal atrophy following treatment of Cushing's disease. Biol Psychiatry 46: 1595-1602.

Starkman MN, Schteingart DE, Schork MA (1981). Depressed mood and other psychiatric manifestations of Cushing's syndrome: relationship to hormone levels. Psychosom Med 43: 3-18.

Stroop JR (1935). Studies of interference in serial verbal reactions. J Exp Psychol 18: 643-662.

Terfehr K, Wolf OT, Schlosser N, Fernando SC, Otte C, Muhtz C et al (2011a). Effects of acute hydrocortisone administration on declarative memory in patients with major depressive disorder: a placebo-controlled, double-blind crossover study. J Clin Psychiatry 72: 1644-1650.

Terfehr K, Wolf OT, Schlosser N, Fernando SC, Otte C, Muhtz C et al (2011b). Hydrocortisone impairs working memory in healthy humans, but not in patients with major depressive disorder. Psychopharmacology (Berl) 215: 71-79.

Tytherleigh MY, Vedhara K, Lightman SL (2004). Mineralocorticoid and glucocorticoid receptors and their differential effects on memory performance in people with Addison's disease. Psychoneuroendocrinology 29: 712-723.

van Rossum EF, Binder EB, Majer M, Koper JW, Ising M, Modell S et al (2006). Polymorphisms of the glucocorticoid receptor gene and major depression. Biol Psychiatry 59: 681-688.

van West D, Van Den Eede F, Del-Favero J, Souery D, Norrback KF, Van Duijn C et al (2006). Glucocorticoid receptor gene-based SNP analysis in patients with recurrent major depression. Neuropsychopharmacology 31: 620-627.

White MG, Bogdan R, Fisher PM, Munoz KE, Williamson DE, Hariri AR (2012). FKBP5 and emotional neglect interact to predict individual differences in amygdala reactivity. Genes Brain Behav 11: 869-878.

Yang X, Ewald ER, Huo Y, Tamashiro KL, Salvatori R, Sawa A et al (2012). Glucocorticoid-induced loss of DNA methylation in non-neuronal cells and potential involvement of DNMT1 in epigenetic regulation of Fkbp5. Biochem Biophys Res Commun 420: $570-575$.

Zaharia MD, Kulczycki J, Shanks N, Meaney MJ, Anisman H (1996). The effects of early postnatal stimulation on Morris watermaze acquisition in adult mice: genetic and maternal factors. Psychopharmacology (Berl) 128: 227-239.

Zannas AS, Binder EB (2014). Gene-environment interactions at the FKBP5 locus: sensitive periods, mechanisms and pleiotropism. Genes Brain Behav 13: 25-37.

Supplementary Information accompanies the paper on the Neuropsychopharmacology website (http://www.nature.com/npp) 